\title{
Variação sazonal de macronutrientes em uma espécie arbórea de cerrado, na Reserva Biológica e Estação Experimental de Mogi-Guaçu, estado de São Paulo, Brasil
}

\author{
Adriana Carrhá Leitão ${ }^{1}$ \\ Osvaldo Aulino da Silva²
}

\begin{abstract}
RESUMO
O presente estudo visou avaliar mensalmente a compartimentação mineral em Ouratea spectabilis (Mart.) Engl. nas diferentes fenofases, no período de agosto de 1995 a julho de 1996, em área de cerrado, na Reserva Biológica e Estação Experimental de Mogi-Guaçu, localizado no município de Mogi-Guaçu, em São Paulo. Foram analisados todos os macronutrientes (N, P, K, Ca, Mg e S) nos compartimentos folha, em 3 estádios de desenvolvimento foliar, ramo, flor e fruto. As observações fenológicas foram realizadas mensalmente em 20 espécimens distribuídos na área de cerrado, sendo consideradas as fenofases brotação, queda foliar, floração e frutificação. A distribuição dos elementos minerais nos compartimentos e nos diferentes estádios de desenvolvimento foliar revelou diferenças significativas e padrões sazonais bem definidos, permitindo identificar a importância de cada nutriente nas diferentes fases do desenvolvimento da planta, e sugerir sobre a capacidade de retranslocação destes elementos e manutenção do balanço nutricional. Face a essas análises, a espécie $O$. spectabilis comporta-se de maneira altamente eficiente na utilização de água e nutrientes, refletindo padrões fenológico e de distribuição que garantem a sua sobrevivência em ambientes de cerrado.
\end{abstract}

Palavras-chave: nutrição mineral, macronutrientes, fenologia, cerrado

\begin{abstract}
The present study aims to evaluate monthly the mineral nutrition presented by the population of Ouratea spectabilis (Mart.) Engl. in different phenophases, from August of 1995 to July of 1996, in a cerrado area of the Reserva Biológica e Estação Experimental de Mogi-Guaçu, located at Mogi-Guaçu City, São Paulo. All the macro elements (N, P, K, Ca, Mg and S) were analyzed on leaves, branches, flowers and fruits compartments, and in 3 leaf development stages. The phenological studies were made monthly in 20 specimens distributed in the cerrado area and phenophases variation (leaf flushing, leaf fall, flowering and fruiting) were analyzed quantitatively. The distribution of the mineral elements among the sampled vegetative parts revealed significant differences and a well defined seasonal pattern, which allows to identify the importance of each nutrient in different developmental phase of the plant, and it suggest about the mineral translocation capacity and its nutritional status. In face of these facts, $O$. spectabilis shows significant efficiency in water and nutrient utilization, reflecting in distribution and phenological patterns that guarantees its survival in cerrado's environments.
\end{abstract}

Keywords: mineral nutrition, macronutrient, phenology, cerrado

${ }^{1}$ Departamento de Botânica, Ecologia e Zoologia, Universidade Federal do Rio Grande do Norte, Natal, RN, Brasil. Rua Dr. Manoel Augusto Bezerra de Araújo, 180 / 09, Ponta Negra, CEP 59.090-430, Natal/RN, Brasil.

${ }^{2}$ Departamento de Botânica, Universidade Estadual Paulista, Rio Claro, SP, Brasil.

Apoio financeiro: $\mathrm{CNPq}$ 


\section{INTRODUÇÃO}

O comportamento nutricional de árvores florestais pode variar apreciavelmente durante seu ciclo, como resultado de mudanças no metabolismo, transporte interno e lavagem causada pela água da chuva (Davy \& Taylor, 1975; Ernst, 1975; Guha \& Mitchell, 1966). Espécies vegetais podem desenvolver mecanismos eficientes de manutenção do metabolismo, para garantir sua sobrevivência em ambientes adversos. A retranslocação de minerais é uma forma de diminuir a perda de nutrientes pelas plantas e permitir a manutenção das atividades metabólicas, principalmente em períodos sujeitos ao estresse nutricional. Rathcke \& Lacey (1985) comentam que a floração, frutificação e germinação requerem uma entrada de energia e nutrientes específicas e que a disponibilidade de recursos e a capacidade da planta na alocação e assimilação destes recursos podem influenciar os padrões fenológicos das espécies.

Em um estudo da nutrição mineral realizado em três espécies de leguminosas freqüentes numa área de cerrado, Anadenanthera falcata, Dalbergia miscolobium Benth. (D. violacea, sin.) e Stryphnodendron adstringens, foram observadas diferenças nutricionais entre os compartimentos e, ainda, foi verificado haver uma grande variabilidade na concentração de um mesmo nutriente para as diferentes espécies (Pagano et al., 1982). Villela \& Lacerda (1992) mencionam que a variação sazonal na concentração dos elementos minerais nas folhas parece estar fortemente relacionada aos mecanismos de absorção e de retranslocação destes nutrientes. Estudos mostram que em florestas tropicais os mecanismos adaptativos de sobrevivência e manutenção do equilíbrio mudam qualitativa e quantitativamente ao longo de gradientes de fertilidade do solo, temperatura, altitude e umidade. Florestas sobre solos mais pobres, altamente intemperizados, teriam desenvolvido mecanismos mais eficientes de conservação do estado nutricional, tais como a retranslocação de elementos minerais de órgãos senescentes. Turner (1977) e Vitousek (1982 e 1984) ressaltaram as diferenças existentes entre os ecossistemas e entre as espécies vegetais, quanto à eficiência na utilização dos nutrientes para a produção de compostos orgânicos, dependendo da disponibilidade daqueles no solo.

O conhecimento dos teores de nutrientes em vários órgãos do vegetal permite inferir sobre as exigências metabólicas desenvolvidas em cada compartimento, fornecendo base para o entendimento dessas variações e suas implicações nas respostas dos vegetais no ecossistema (Mendes, 1996). Existem poucos trabalhos que relacionam variações no estoque de nutrientes nas diferentes fenofases apresentadas pelas espécies vegetais. Tais estudos permitem conhecer sobre as adaptações específicas de plantas quanto à alocação de recursos nas diferentes fenofases e em diferentes biomas.

$\mathrm{O}$ presente estudo avaliou o comportamento nutricional em uma espécie representante do cerrado paulista, através de análises dos teores de minerais em três estádios de expansão foliar, além de ramos, flores e frutos.

\section{MATERIAL E MÉTODOS}

O estudo foi realizado na Reserva Biológica e Estação Experimental de MogiGuaçu $\left(22^{\circ} 15^{\prime}-16^{\prime}\right.$ S e $47^{\circ} 08^{\prime}-12^{\prime}$ W). A análise dos dados de precipitação e temperatura do período de 1987 a 1996 permitiu confirmar que o clima local corresponde ao Cw'a de Köppen (1963), ou B3 r B'3 a' de Thornthwaite (1948), in Cunha (1992), caracterizado como mesotérmico, úmido, de inverno seco, com pouco ou nenhum déficit hídrico e com excesso no verão, sendo as condições hídricas da área afetadas mais pela distribuição das chuvas do que pelo total anual de precipitação. O clima para o ano de estudo foi analisado a partir do diagrama ombrotérmico construído para a área (Fig. 1), 


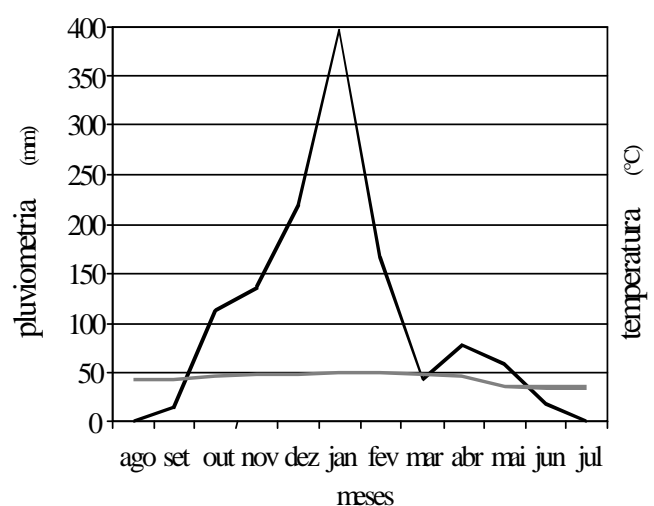

Figura 1 - Diagrama ombrotérmico $(\mathrm{P}=2 \mathrm{~T})$ para a área da Reserva Biológica e Estação Experimental de MogiGuaçu/SP, referente ao período de agosto/1995 a julho/ 1996.

onde é possível observar um período chuvoso bem marcado, com índices pluviométricos acima de $100 \mathrm{~mm}$ de outubro/1995 a fevereiro/ 1996, e um déficit hídrico nos meses de agosto/ 1995, junho e julho/1996. O período de seca concentrado entre junho e agosto é característico para esta região (Leitão, 1998).

Para a escolha da espécie foram consideradas características como frequiência e importância fitossociológica (Gibbs et al., 1983; Silberbauer-Gottsberger \& Eiten, 1983; Batista \& Couto, 1992) em ambientes de cerrado. A espécie em estudo, Ouratea spectabilis (Mart.) Engl., também conhecida popularmente como Murici-bravo ou Batiputá, é pertencente à Família Ochnaceae.

Mensalmente foram sorteados, entre vinte espécimens previamente escolhidos, três indivíduos de $O$. spectabilis, onde foram amostrados os compartimentos folhas, ramos, flores e frutos. Os materiais coletados dos três indivíduos foram reunidos numa única amostra por compartimento. No compartimento folha foram amostradas folhas da base (estádio 1), região mediana (estádio 2) e extremidade do ramo (estádio 3), obtendo-se material em diferentes estádios de desenvolvimento. Neste caso, sendo feitas análises sazonais, nem sempre foi possível detectar as variações esperadas nos teores de nutrientes nas folhas jovens e adultas, exceto quando estes estádios tiveram presença significativa na maioria dos meses analisados. Os materiais coletados foram secos em estufa a $70^{\circ} \mathrm{C}$, até peso constante, em seguida moídos para posterior análise de nutrientes minerais.

As determinações dos macronutrientes nitrogênio, fósforo, potássio, cálcio e magnésio seguiram a metodologia proposta por Malavolta et al. (1989); enquanto que para o enxofre foi utilizado o método proposto por Vitti (1988). Para cada amostra foram feitas três repetições, para obtenção de uma média.

As informações fenológicas foram avaliadas quantitativamente, utilizando-se uma nota dentro de uma escala que varia entre $0 \mathrm{e}$ 4, segundo a metodologia proposta por Fournier (1974). Foram realizadas observações mensais dos estádios brotação, queda foliar, floração e frutificação (frutos verdes e frutos maduros) em vinte espécimens de $O$. spectabilis.

As coletas para o estudo da compartimentação mineral foram realizadas de agosto de 1995 a julho de 1996; e as observações fenológicas, de agosto de 1995 a dezembro de 1996.

Para a análise dos resultados foi realizada estatística não-paramétrica. O Teste KruskalWallis, seguido do Teste Jonckheere (Campos, 1983), foi utilizado para verificar possíveis diferenças nos teores de nutrientes minerais entre os compartimentos (folha e ramo) e entre os estádios foliares. A possível sazonalidade nos teores de nutrientes minerais foi avaliada estatisticamente, comparando-se as médias obtidas dos valores de cada nutriente nos meses do período seco (de abril a setembro) e do período chuvoso (de outubro a março). A Correlação de Spearman (R) foi utilizada para correlacionar as fenofases apresentadas pela espécie com as variações nos teores de nutrientes nas folhas e ramos.

\section{RESULTADOS E DISCUSSÃO}

A espécie $O$. spectabilis não apresentou comportamento sazonal significativo para os nutrientes analisados. Muitas plantas de cerrado adquiriram características 


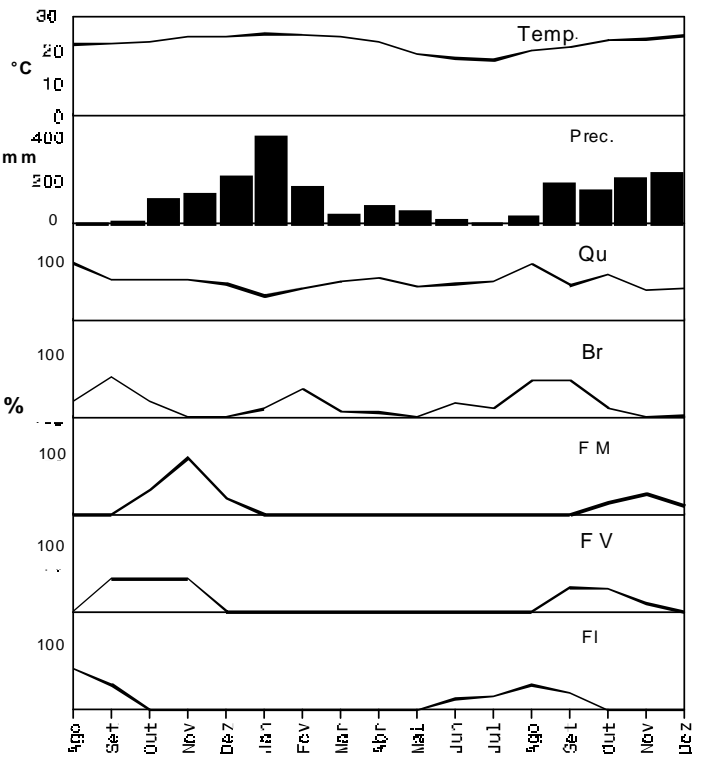

Figura 2 - Fenograma de $O$. spectabilis em porcentagens de floração (Fl), frutos verdes (FV), frutos maduros (FM), brotação $(\mathrm{Br})$ e queda foliar $(\mathrm{Qu}) \mathrm{e}$, valores mensais de precipitação $(\mathrm{mm})$ e temperatura $\left({ }^{\circ} \mathrm{C}\right)$, com base em observações realizadas na Reserva Biológica e Estação Experimental de Mogi-Guaçu, de agosto/1995 a dezembro/ 1996.

escleromórficas, que podem atuar no sentido de impedir ou dificultar a perda de nutrientes via cutícula foliar através da lavagem pelas águas das chuvas; além disto, a eficiência na retranslocação de nutrientes parece contribuir para a manutenção do estado nutricional da planta.

Em setembro, a espécie em estudo apresentou o maior índice de intensidade no brotamento de folhas (Fig. 2), época em que a planta atinge seu pico na concentração de nitrogênio nas folhas da ponta do ramo (Fig. 3a). Também foram observadas estatisticamente concentrações mais elevadas de nitrogênio nas folhas mais jovens, sendo que estes teores diminuem à medida que estas folhas ficam mais próximas ao estado de senescência $(p<0,01)$. Do mesmo modo, Medeiros \& Haridasan (1985) verificaram para espécies de cerrado que em novembro, quando as folhas estavam recém-expandidas, os teores de nitrogênio foram mais elevados que nos estádios mais desenvolvidos. Isto justifica a boa mobilidade do nitrogênio, podendo-se retranslocar das folhas mais velhas para ser reutilizado em folhas mais novas (Raij, 1991), como foi observado também por Toslma et al. (1987) em folhas de espécies ocorrentes em savana. Este nutriente tem papel importante na formação e desenvolvimento das gemas floríferas e frutíferas (Coelho \& Verlengia, 1973), bem como no crescimento vegetativo e formação de sementes (Ferreira et al. 1993). Apesar da aparente eficiência na absorção do nitrogênio, estatisticamente não foi observada nenhuma diferença significativa entre folhas e ramos, bem como não foi observado nenhum destaque nos valores dos compartimentos flor e fruto (Fig. 3b).

O fósforo é essencial para a formação de frutos e sementes (Raij, 1991; Camargo \& Silva, 1975). Neste estudo, ficou evidenciada uma correlação positiva entre a fenofase fruto maduro e a concentração de fósforo nas folhas e ramos $(\mathrm{R}=0,72, \mathrm{p}<0,01)$, mostrando uma eficiência na demanda e armazenamento deste elemento pela planta, no período de amadurecimento dos frutos e dos embriões (Figs. 2 e 4b). Em outubro, o suprimento dos

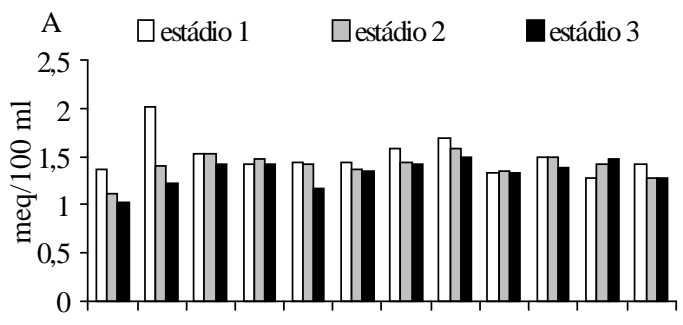

ago set out nov dez jan fev mar abr mai jun jul

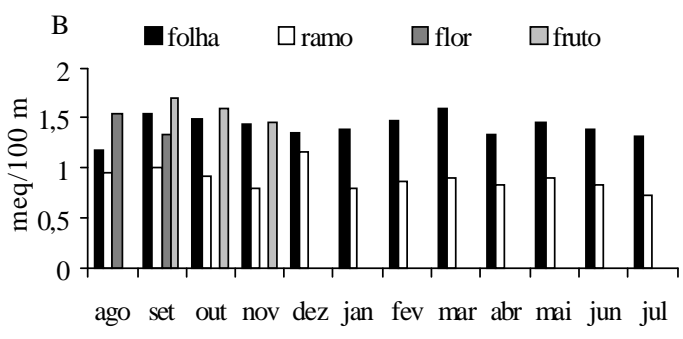
meses

Figura 3 - Variação mensal dos teores de nitrogênio na espécie $O$. spectabilis, em área de cerrado da Reserva Biológica e Estação Experimental de Mogi-Guaçu, SP. A. Concentração nas folhas da ponta (estádio 1), região mediana (estádio 2) e base do ramo (estádio 3). B. Concentração nos compartimentos folha, ramo, flor e fruto. 
Variação sazonal de macronutrientes em uma espécie arbórea de cerrado, na Reserva Biológica e Estação Experimental de Mogi-Guaçu, estado de São Paulo, Brasil

frutos com relação a este nutriente atinge quase quatro vezes os teores encontrados nas folhas e ramos (Fig. 4b). Os altos níveis de fósforo assimilados pela planta, nos períodos seco e chuvoso, podem significar um importante mecanismo de manutenção do estado nutricional e, conseqüentemente, metabólico da planta, no momento em que esta está investindo sua energia na produção de folhas, ramos, ou mesmo, preparando-se para a fase reprodutiva. É de conhecimento geral que os níveis deste elemento no solo de cerrado são baixos e, portanto, a demanda de abastecimento pode estar relacionada à oferta proporcionada pela matéria orgânica, enriquecida pela deposição de material vegetal (fitomassa), especialmente por queda de folhas nos meses anteriores à estação chuvosa (Mendes, 1996). Neste caso, esta espécie parece apresentar-se adaptada a situações de baixo suprimento de fósforo no solo e, provavelmente, dispõe de certas adaptações que permitem a sobrevivência em tais ambientes.

Além disso, o fósforo é considerado um nutriente de boa mobilidade, sendo facilmente
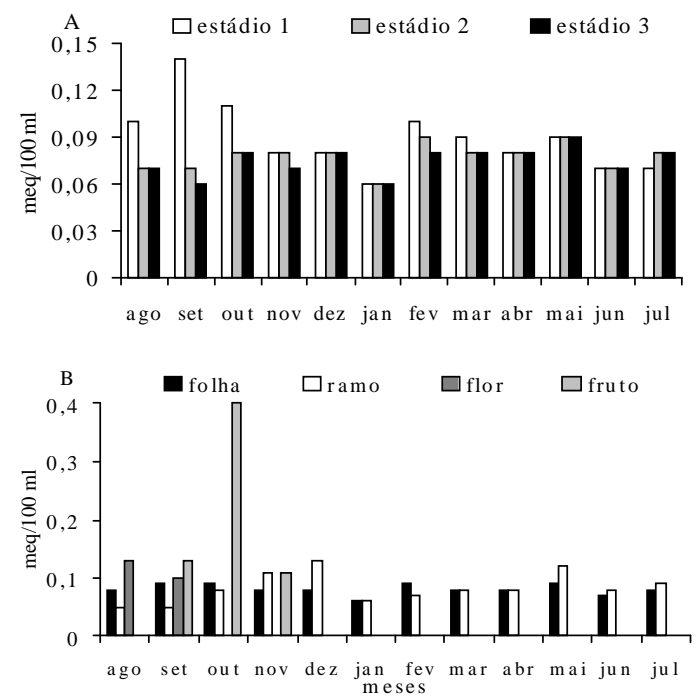

Figura 4 - Variação mensal dos teores de fósforo na espécie O. spectabilis, em área de cerrado da Reserva Biológica e Estação Experimental de Mogi-Guaçu, SP. A. Concentração nas folhas da ponta (estádio 1), região mediana (estádio 2) e base do ramo (estádio 3). B. Concentração nos compartimentos folha, ramo, flor e fruto. redistribuído a partir de órgãos mais velhos para órgãos em expansão (Larcher, 2000; Malavolta, 1980). No presente estudo não foram encontrados diferenças significativas na concentração deste elemento entre os estádios foliares analisados, e entre os compartimentos folhas e ramos. Entretanto, ficou evidenciado um aumento pontual nos teores de fósforo nas folhas da ponta do ramo em setembro (Fig. 4a), período em que a planta atinge seu máximo na produção de novas folhas (Fig. 2). Visto que os níveis de fósforo em solos de cerrado são comprometidos pelos_baixos valores de $\mathrm{pH}$, e altas concentrações de alumínio, o que diminui a disponibilidade deste mineral (Malavolta \& Kliemann, 1985; Lopes, 1983; Kamprath, 1977; Volkweiss \& Raij, 1976; Goodland, 1971), sugere-se que a espécie $O$. spectabilis esteja adaptada a estas condições, apresentando um importante mecanismo de manutenção do estado nutricional e, conseqüentemente, metabólico, que permite a sobrevivência da planta em tais ambientes.

A maior parte do potássio é absorvida pelas plantas durante a fase de crescimento vegetativo (Raij, 1991), pois este tem papel fundamental na fotossíntese e síntese de carboidratos (Yamada, 1987). Para a espécie em estudo, foram encontradas diferenças significativas nos teores de potássio entre os três estádios foliares analisados (Fig. 5a), sendo evidenciadas concentrações mais elevadas em folhas mais jovens $(\mathrm{p}<0,01)$. Villela \& Lacerda (1992) estudando as espécies de cerrado Vochysia rufa e Curatella americana, também encontraram durante o pico de brotamento foliar, os níveis mais elevados de potássio nas folhas jovens, sugerindo a reabsorção do elemento antes da abscisão. Uma vez que o potássio é um elemento altamente móvel no floema, sua utilização é eficiente no sentido de ser prontamente redistribuído das folhas para órgãos mais novos (Larcher, 2000; Malavolta, 1980).

No presente trabalho, ficaram evidenciadas concentrações elevadas de potássio nas flores e nos frutos (Fig. 5b). As 
análises estatísticas revelaram uma correlação negativa $(R=-0,64, p<0,05)$ entre a fenofase floração e a concentração de potássio em folhas e ramos (Figs. 2 e 5b). Assim, visto que o potássio é redistribuído para órgãos em crescimento e se concentra em grande parte nos frutos verdes (Raij, 1991), é sugerido haver uma grande translocação deste elemento, das folhas e ramos, para as flores; e uma preparação da planta para a fase subseqüente, a produção dos frutos. Embora tenha sido encontrado teores mais elevados nas folhas do que nos ramos $(\mathrm{p}<0,01)$, em dezembro é notado um pico na concentração de potássio nos ramos, chegando a quase três vezes os valores encontrados nas folhas (Fig. 5b), o que pode representar uma reposição e armazenamento deste nutriente no final das fenofases reprodutivas.

A espécie em estudo apresentou diferenças significativas $(p<0,01)$ nas concentrações de cálcio entre os estádios de desenvolvimento foliar, sendo mais elevados os valores de cálcio em folhas mais velhas (Fig. 6 a), pois sendo um elemento de baixa mobilidade nas plantas, não sendo transportado
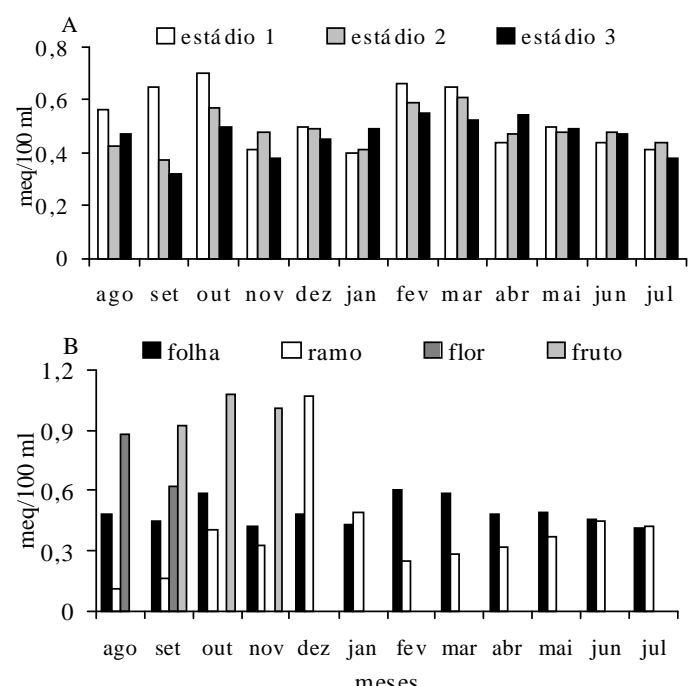

Figura 5 - Variação mensal dos teores de potássio na espécie $O$. spectabilis, em área de cerrado da Reserva Biológica e Estação Experimental de Mogi-Guaçu, SP. A. Concentração nas folhas da ponta (estádio 1), região mediana (estádio 2) e base do ramo (estádio 3). B. Concentração nos compartimentos folha, ramo, flor e fruto. pelo floema com facilidade, ele é encontrado em maior concentração em folhas maduras e senescentes (Larcher, 2000). Depois de sua localização nestes sítios, torna-se muito imóvel sofrendo a influência de outros cátions $(\mathrm{Mg}$, Mn e Zn), que podem comprometer a sua troca (Malavolta, 1980). Sobrado \& Medina (1980) encontraram os maiores valores de cálcio para as folhas mais velhas de espécies escleromórficas da Amazônia.

Além da importante relação com a resistência mecânica dos tecidos, o cálcio é indispensável para a germinação do pólen e o crescimento do tubo polínico, sendo importante para a floração (Epstein, 1975). Em $O$. spectabilis, nos meses de maio e junho foi observado um aumento na concentração deste nutriente no compartimento ramo, seguido de uma notável redução no mês de julho, agosto e setembro; o que pode estar relacionado com um aumento na demanda deste elemento pela planta, em primeira instância, seguido por utilização em potencial no período de floração (Fig. 6b). Segundo Chapin et al. (1980) e Camargo \& Silva (1975), a diminuição dos teores desse elemento no caule, durante a
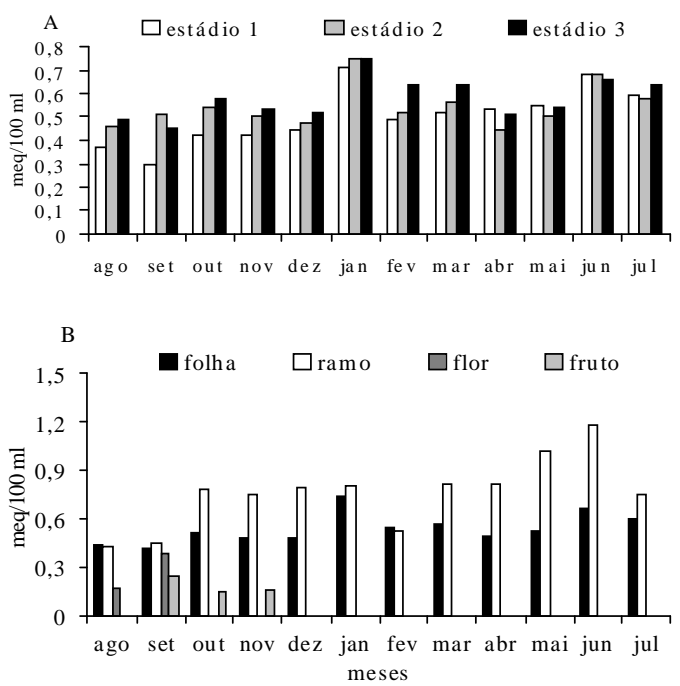

Figura 6 - Variação mensal dos teores de cálcio na espécie O. spectabilis, em área de cerrado da Reserva Biológica e Estação Experimental de Mogi-Guaçu, SP. A. Concentração nas folhas da ponta (estádio 1), região mediana (estádio 2) e base do ramo (estádio 3). B. Concentração nos compartimentos folha, ramo, flor e fruto. 
Variação sazonal de macronutrientes em uma espécie arbórea de cerrado, na Reserva Biológica e Estação Experimental de Mogi-Guaçu, estado de São Paulo, Brasil

estação de crescimento, sugere ser este órgão armazenador de cálcio. Ou ainda, pode-se inferir haver um maior direcionamento do nutriente absorvido do solo, para as flores, uma vez que este elemento tem baixa mobilidade na planta.

O magnésio é um elemento móvel na planta (RAIJ, 1991). Entretanto, é comum encontrar maior concentração de magnésio em folhas mais velhas, do que em folhas jovens (Malavolta, 1980). A espécie em estudo apresentou diferenças significativas entre os estádios foliares $(p<0,01)$, sendo mais elevados os teores em folhas mais velhas (Fig. 7a). Também, ficou evidenciado que o compartimento ramo é um armazenador deste nutriente, apresentando teores bem mais elevados do que nas folhas, na maior parte do ano $(\mathrm{p}<0,01)$, o que pode ser uma característica de $O$. spectabilis (Fig. 7b).

Apesar de, estatisticamente, não ser detectado uma relação entre a concentração de magnésio nos diferentes compartimentos e as fenofases analisadas, observa-se uma redução deste nutriente nos meses de agosto e setembro nos compartimentos folhas e

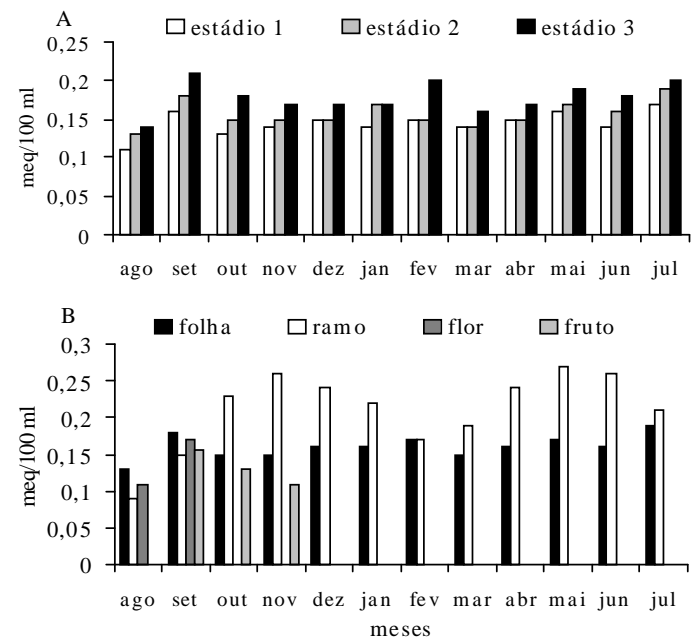

Figura 7 - Variação mensal dos teores de magnésio na espécie $O$. spectabilis, em área de cerrado da Reserva Biológica e Estação Experimental de Mogi-Guaçu, SP. A. Concentração nas folhas da ponta (estádio 1), região mediana (estádio 2) e base do ramo (estádio 3). B. Concentração nos compartimentos folha, ramo, flor e fruto. ramos, o que parece estar relacionado a maior utilização deste elemento para a realização de suas funções reprodutivas, principalmente da floração e da produção de frutos verdes. Uma das funções importantes do magnésio, como elemento central da molécula de clorofila, é a sua participação na fotossíntese. É também considerado específico na ativação de diversos sistemas enzimáticos das plantas, tais como ativação de enzimas relacionadas com o metabolismo dos carboidratos (Camargo \& Silva, 1975).

$\mathrm{O}$ enxofre tem papel fundamental na síntese de gorduras, óleos e proteínas, estando relacionado com o crescimento vegetal, sendo muito importante para a frutificação (Camargo \& Silva, 1975). A baixa mobilidade no floema é característica deste mineral. Embora, de acordo com Larcher (2000), o sítio de acumulação do enxofre seja nas folhas e sementes, sendo encontrado em maior concentração em folhas maduras, para $O$. spectabilis não foram obtidas diferenças significativas na concentração deste elemento, entre os estádios foliares (Fig. 8a), nem entre os compartimentos folha e ramo (Fig. 8b).
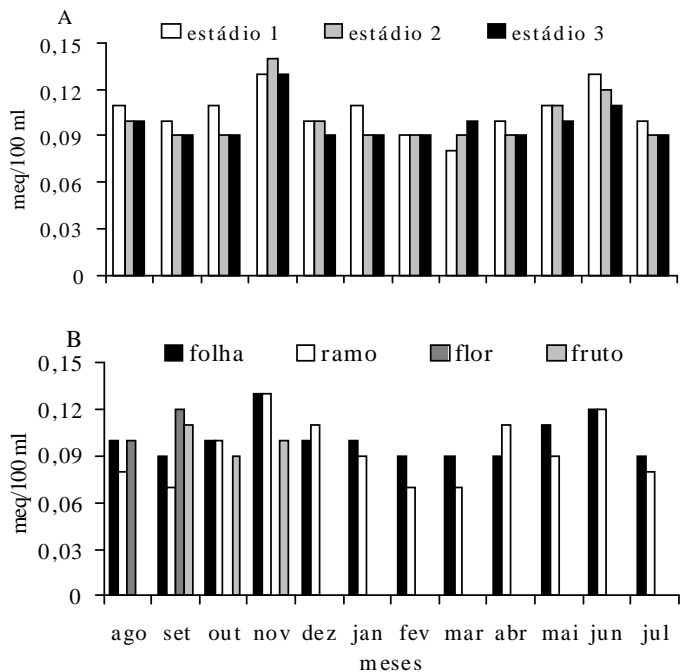

Figura 8 - Variação mensal dos teores de enxofre na espécie O. spectabilis, em área de cerrado da Reserva Biológica e Estação Experimental de Mogi-Guaçu, SP. A. Concentração nas folhas da ponta (estádio 1), região mediana (estádio 2) e base do ramo (estádio 3). B. Concentração nos compartimentos folha, ramo, flor e fruto. 
Os solos sob cerrado apresentam características químicas e físicas muito particulares, como a sua elevada acidez. Particularmente na área da Reserva o $\mathrm{pH}$ pode variar entre 3,0 e 5,5 até $50 \mathrm{~cm}$ de profundidade (Leitão, 1998). Esta forte acidez é devida em boa parte aos altos níveis de alumínio presentes nestes solos, uma condição característica nestes ambientes. A baixa capacidade de troca catiônica, baixa soma de bases e a alta saturação por $\mathrm{Al}^{3+}$ são fatores que caracterizam estes solos como profundamente distróficos, características estas que limitam a absorção de nutrientes pelas plantas (Coutinho, 1990). Fatores edáficos, aliados ao regime climático da área, são ícones importantes agindo como pressão de seleção, sendo determinantes na evolução de características morfológicas e fisiológicas especializadas em toda a biota, para que possa melhor aproveitar os recursos, garantindo assim a continuidade de cada espécie neste habitat.

No presente estudo, a análise sazonal das variações nos teores de elementos minerais nos compartimentos e nos diferentes estádios de desenvolvimento foliar permitiu inferir sobre a maneira que a espécie está respondendo às condições impostas pelo meio físico e químico, como estão sendo distribuídos, estocados e retranslocados os nutrientes, além de fornecer subsídios para o conhecimento das exigências nutricionais requeridas em cada fenofase observada em $O$. spectabilis.

\section{AGRADECIMENTOS}

Ao Benedito Domingues do Amaral pela ajuda nas análises estatísticas; ao Instituto de Botânica de São Paulo, por permitir o acesso à Reserva Biológica e Estação Experimental de Mogi-Guaçu.

\section{REFERÊNCIAS BIBLIOGRÁFICAS}

Batista, E. A. \& Couto, H. T. Z. 1992. Influência de fatores químicos do solo sobre o desenvolvimento das espécies florestais mais importantes do cerrado da
Reserva Biológica de Mogi-Guaçu, SP. Revista do Instituto Florestal 4 (1): 324-329.

Camargo, P. N. \& Silva, O. 1975. Manual de adubação foliar. São Paulo, Herba, $258 \mathrm{p}$.

Campos, H. 1983. Estatística experimental não-paramétrica. Piracicaba, ESALQ/ USP, p.201-232.

Chapin, F. S. III, Johnson, D. A. \& McKendrick, J. D. 1980. Seasonal movement of nutrients in plants of differing growth form in a Alaskan tundra ecosystem: implication for herbivory. Journal of Ecology 68 (1): 189-209.

Coelho, F. S. \& Verlengia, F. 1973. Fertilidade do solo. Campinas, Instituto Campineiro de Ensino Agrícola, 384 p.

Coutinho, L. M. 1990. Fire in the Ecology of the Brazilian Cerrado. In: Goldammer, J. G. (ed.). Fire in the Tropical Biota. Berlin, Springer-Verlag. Ecological Studies 84: 82-105.

Cunha, G. R. 1992. Balanço hídrico climático. In: Bergamaschi, H. (ed.). Agrometeorologia aplicada à irrigação. Porto Alegre, Ed. da UFRGS, p.63-84.

Davy, A. J. \& Taylor, K. 1975. Seasonal changes in the inorganic nutrient concentrations in Deschampsia caespitosa (L.) Beauv. in relation to its tolerance of contrasting soils in the Chiltern Hills. Journal of Ecology 63 (1): 27-39.

Epstein, E. 1975. Nutrição mineral das plantas: princípios e perspectivas. São Paulo, EDUSP, 344 p.

Ernst, W. 1975. Variation in the mineral contents of leaves of trees in Miombo Woodland in south central Africa. Journal of Ecology 63: 801-807.

Ferreira, M. E., Castellane, P. D. \& Cruz, M. C. P. 1993. Nutrição e adubação de hortaliças. Piracicaba, POTAFOS, 480 p. 
Variação sazonal de macronutrientes em uma espécie arbórea de cerrado, na Reserva Biológica e

Fournier, L. A. 1974. Un método cuantitativo para la medición de características fenológicas en árboles. Turrialba 24: 422-423.

Gibbs, P. E., Leitão Filho, H. F. \& Shepherd, G. 1983. Floristic composition and community structure in an area of cerrado in SE Brazil. Flora 173: 433-449.

Goodland, R. 1971. Oligotrofismo e alumínio no cerrado. III Simpósio Sobre o Cerrado. São Paulo, Ed. Edgard Blücher, p.44-60.

Guha,M. M. \& Mitchell, R. L. 1966. The trace and major element composition of the leaves of some deciduous trees. II. Seasonal changes. Plant and Soil 24: 90-112.

Kamprath, E. J. 1977.Phosphorus fixation and availability in highly weathered soils. $I V$ Simpósio Sobre o Cerrado. Belo Horizonte, Ed. Itatiaia Ltda., p.333-347.

Larcher, W. 2000. Ecofisiologia Vegetal. São Carlos, RiMa Artes e Textos, 531 p.

Leitão, A. C. 1998. Nutrição mineral, fenologia e distribuição da população de Ouratea spectabilis (Mart.) Engl., em área de cerrado na Reserva Biológica de Mogi-Guaçu, SP. Rio Claro, Instituto de Biociências, UNESP, 131 p. Dissertação de Mestrado.

Lopes, A. S. 1983. Solos sob "cerrado": características, propriedades e manejo. Piracicaba, POTAFOS, 162 p.

Malavolta, E. \& Kliemann, H. J. 1985. Desordens nutricionais no cerrado. Piracicaba, POTAFOS, 136 p.

Malavolta, E. 1980. Elementos de nutrição mineral de plantas. São Paulo, Ed. Agronômica Ceres, 251 p.

Malavolta, E., Vitti, G. C. \& Oliveira, S. A. 1989. Avaliação do estado nutricional das plantas: princípios e aplicações. Piracicaba, POTAFOS, $201 \mathrm{p}$.

Medeiros, R. A. \& Haridasan, M. 1985. Seasonal variations in the foliar

Rodriguésia 55 (84): 127-136. 2004 concentrations of nutrients in some aluminium accumulating and nonaccumulating species of the cerrado region of central Brazil. Plant and Soil 88: $433-436$.

Mendes, J. A. 1996. Distribuição espacial, fenologia e compartimentação de três espécies de Qualea (Vochysiaceae) na Reserva Biológica de Mogi-Guaçu $S P$. Rio Claro, Instituto de Biociências, UNESP, 201 p. Tese de Doutorado.

Pagano, S. N., Cesar, O. \& Santos, P. S. 1982. Compartimentação de nutrientes em órgãos vegetativos aéreos em três espécies de leguminosas num ecossistema de cerrado. Silvicultura em São Paulo 16-A (1): 536-543.

Raij, B. van. 1991. Fertilidade do solo e adubação. São Paulo, Piracicaba, Ed. Agronômica Ceres, POTAFOS, 343 p.

Rathcke, B. \& Lacey, E. P. 1985. Phenological patterns of terrestrial plants. Annual Review Ecology and Systematics 16: 179-214.

Silberbauer-Gottsberger, I. \& Eiten, G. 1983. Fitossociologia de um hectare de cerrado. Brasil Florestal 54: 55-83.

Sobrado, M. A. \& Medina, E. 1980. General morphology, anatomical structure, and nutrient content of sclerophyllous leaves of the 'Bana' vegetation of Amazonas. Oecologia (Berl.) 45 (3): 341-345.

Tolsma, D. J., Ernst, W. H. O., Verweij, R. A. \& Vooijs, R. 1987. Seasonal variation of nutrient concentrations in a semi-arid savanna ecosystem in Botswana. Journal of Ecology 75 (3): 755-770.

Turner, J. 1977. Effect of nitrogen availability on nitrogen cycling in a Douglas-fir stand. Forest Science 23: 307-316.

Villela, D. M. \& Lacerda, L. D. 1992. Dinâmica de elementos minerais em folhas de duas espécies arbóreas de cerrado. Revista Brasileira de Biologia 52 (1): 151-160. 
Vitousek, P. M. 1982. Nutrient cycling and nutrient efficiency. Am. Nat 119 (4): 553 572.

Vitousek, P. M. 1984. Litterfall, nutrient cycling, and nutrient limitation in tropical forests. Ecology 65 (1): 285-298.

Vitti, G. C. 1988. Avaliação e interpretação do enxofre no solo e na planta. Jaboticabal, FUNEP, 37 p.

Volkweiss, S. J. \& Raij, B. van. 1977. Retenção e disponibilidade de fósforo em solos. $I V$ Simpósio Sobre o Cerrado. Belo Horizonte, Ed. Itatiaia Ltda., p.317-332.

Yamada, T. 1987. Potássio: dinâmica e disponibilidade no solo. In: Fernandes, F. M. \& Nascimento, V. M. (eds.). Curso de atualização em fertilidade do solo. Campinas, Fundação Cargill, p.183-205. 